\title{
Exact Solution of Two-Dimensional Unsteady Airflow in an Inclined Trachea
}

\author{
Esam. A. Ahmed Alnussairy ${ }^{1,2}$, Ahmed Bakheet ${ }^{1} \&$ Norsarahaida Amin ${ }^{1}$ \\ ${ }^{1}$ Department of Mathematical Science, Faculty of Science, Universiti Teknologi Malaysia, Malaysia \\ ${ }^{2}$ Department of Mathematical Science, Faculty of Computer and Mathematics, Wasit University, Iraq \\ Correspondence: Norsarahaida Amin, Department of Mathematical Science, Faculty of Science, Universiti \\ Teknologi Malaysia, 81310 Skudai, Johor, Malaysia. E-mail: norsarahaida@utm.my
}

Received: October 24, 2015

Accepted: November 6, 2015

Online Published: January 5, 2016

doi:10.5539/mas.v10n1p191

URL: http://dx.doi.org/10.5539/mas.v10n1p191

\begin{abstract}
The exact solution of the two-dimensional momentum and continuity equations governing the unsteady airflow in an inclined trachea was carried out. The oscillating airflow was described by setting one side of the boundaries be a periodic pressure function. The solution was obtained using Bromwich integral. The present results show that the inclination angle $\theta$ and gravitational force g reduces the pressure drop and has a greater effect on the velocity profile of airflow from the trachea to the lungs. Therefore, sleeping in a horizontal position may lead to negative effects for many patients. However, the inclined position is better, and it is dependent on the slope angle position taking, the benefits of gravitational force and utilizing it to improve the breathing of the body. These results are of help in breathing problems, mild sleep apnea, snoring, asthma and chronic obstructive pulmonary disease.
\end{abstract}

Keywords: exact solution, inclined trachea, unsteady airflow, Bromwich integral

\section{Introduction}

Nowadays, predicting and understanding in depth of the mathematical modelling phenomena development in life science and physiology has increased dramatically. Chong et al. (2015) used mathematical models in the medical industry to understand the dynamics of chronic viral infection. Many researchers applied mathematical models to solve problems in different branches of science (Orakbayev et al., 2015; Shangytbayeva et al., 2015; Stroiteleva \& Vukovich, 2015; Efimov et al., 2015).

In recent years, inclined bed therapy (IBT) has been the subject of ongoing research. It is a new therapy introduced by Andrew Fletcher (1990), (Billen \& Ting, 2013; Inclined Bed Therapy, 2013; Life \& Gravity, 2013). The key to this therapy is to maximize the ability of the body to perform on its own without introducing harmful chemicals or other substances. The advantage of the technique is clear for many of the diseases like breathing problems, mild sleep apnea, snoring, asthma and chronic obstructive pulmonary disease (Rowley et al., 2009; Van Vliet, Ellis, \& Hila, 2005; Ragavan, Evrensel, \& Krumpe, 2010).

Investigators have observed six distinct tracheal shapes from a study of 200 patients by Mehta and Myat (1984) which are elliptical, C-shaped, U-shaped, D-shaped, triangular and circular O-shaped. As well, Terho et al. (1987) collected the seventh and twelfth trachea ring from 205 autopsies. They also observed six distinct shapes. The length of the trachea is about 11-14 cm long connecting the crocodiles cartilage in the larynx to the primary bronchi of the lungs. Its cross-sectional diameter in normal human adults is $1.3-2.5 \mathrm{~cm}$ in the coronal plane and $1.3-2.7 \mathrm{~cm}$ in the sagittal plane. The diameters for females are slightly smaller (Tu, Inthavong and Ahmed, 2013). It is an almost rigid organ containing 16 to 20 tracheal rings that hold and support the trachea, preventing it from collapsing in on itself, but also providing some flexible movement for any neck movement. The main role of the cartilaginous tracheal structures is to maintain the windpipe open despite the inter-thoracic pressure during respiratory movements by Roberts et al. (1998). Also, it kept the airway free of foreign material through coughing as well as intrinsic defence mechanisms and the innate cellular and acquired immune responses (Satpahi, Kumar, \& Chandra, 2003).

A few researchers had investigated the effect of the slope angle position in the trachea, such as VanVliet et al. (2005). An experimental study was conducted to investigate the effect of angle and different types of oscillations 
on simulant mucous velocity in a flexible tube. It is similar in diameter to the adult human trachea using a repeated-measures design in a tube and mucous simulant model for different angles of $0^{\circ}, 30^{\circ}, 60^{\circ}$, and $90^{\circ}$. Symmetrical oscillation was applied in both the transverse and longitudinal directions with frequencies of 5,15 and $25 \mathrm{~Hz}$ at amplitudes of $1 \mathrm{~mm}$ and $2 \mathrm{~mm}$ peak-to-peak. The commercially available oscillator asymmetrical oscillation was applied using repeated cycles of slow acceleration and fast deceleration in the longitudinal direction at $0^{\circ}$ and $30^{\prime \prime}$ downward and up a $5^{\circ}$ slope using a custom-built apparatus. They found simulant mucous velocity increased significantly with increasing angle. At an angle of only $30^{\circ}$ simulant, mucous velocity had already reached $50 \%$ of its maximum value at $90^{\circ}$ with the support of gravity to assist in secretion clearance.

Clearance of airway mucus during a cough is most effective with more gel-like mucus when the trachea is situated at angles $\left(30^{\circ}, 45^{\circ}\right)$ larger than horizontal position (Ragavan, Evrensel, \& Krumpe, 2010). They used experimental studies to investigate the effect of some parameters on the displacement of mucus simulant aliquot during simulated cough in a rigid tracheal model like mucus simulant elasticity and superimposed airflow oscillations and by placing trachea at larger slope angles with respect to horizontal position. Movements of two types of mucus simulants, (patients with severe breathing diseases and representative of healthy individuals) during simulated cough events were measured with and without superimposed airflow oscillations at $0^{\circ}, 15^{\circ}, 30^{\circ}$, and $45^{\circ}$ angles of a plexiglass D-shaped tracheal model having slightly larger dimensions than adult human trachea at low cough velocities $(5-30 \mathrm{~m} / \mathrm{s}$ range). Their results indicated that the effect of the body position during a cough can facilitate the expiratory muscle function and might alter the shape of mucus secretions in the central airways. In other words, increasing average cough velocity at a higher incline angle $\left(30^{\circ} 45^{\circ}\right)$ of the trachea compared with the horizontal position.

Knowledge about airflow in human airways was known as the alternative source that helps in the treatment for breathing patients. Mathematical model describes the dynamics of airflow motion in the trachea through the solution of the momentum and continuity equations. Obtaining the exact solutions, on the other hand, is crucial for many reasons. They provide a standard for checking the accuracies of many approximate methods such as numerical or empirical. Although, currently, computer techniques make the complete integration of momentum, and continuity equations feasible, the accuracy of the results can be established only by a comparison with an exact solution.

A few researchers have tried to find analytical solutions for airflow velocity in the human respiratory instance. Kongnuan and Pholuanghad (2012) proposed a mathematical modelling of the airflow in a human upper respiratory tract, including oral cavity, nasopharynx region and trachea. The airflow can be described as an incompressible, laminar, Newtonian fluid, which has constant density and viscosity without the effects of any external force. The governing equations for the oscillating two-dimensional airflow are the continuity and momentum equations in the Cartesian coordinate system which have been solved using the analytical method of a Fourier series-based and derived from consulting the research of Tsangaris and Vlachakis (2003).

The objective of the present study is to investigate the effect of the inclination angle and the gravitational force of the airflow in the trachea using Bromwich integral.

\section{Method}

\subsection{Governing Equations}

Consider the unsteady airflow in a two-dimensional, incompressible, laminar, Newtonian fluid of constant density and viscosity in a long straight trachea. Let $(x, y)$ be the Cartesian coordinates of any point in the airflow domain in trachea (D-shaped), where $x$-axis is along the bottom of the trachea and is the vertical of the trachea, while $L, h$ length and width are measured on $x$-axis, $y$-axis of the considered region respectively. The momentum and continuity equations of unsteady airflow form can be written as

$$
\begin{aligned}
& \frac{\partial u}{\partial x}+\frac{\partial v}{\partial y}=0 \\
& \rho\left(\frac{\partial u}{\partial t}+u \frac{\partial u}{\partial x}+v \frac{\partial u}{\partial y}\right)=-\frac{\partial p}{\partial x}+\mu\left(\frac{\partial^{2} u}{\partial x^{2}}+\frac{\partial^{2} u}{\partial y^{2}}\right)+\rho g_{x} \sin \theta \\
& \rho\left(\frac{\partial v}{\partial t}+u \frac{\partial v}{\partial x}+v \frac{\partial v}{\partial y}\right)=-\frac{\partial p}{\partial y}+\mu\left(\frac{\partial^{2} v}{\partial x^{2}}+\frac{\partial^{2} v}{\partial y^{2}}\right)-\rho g_{y} \cos \theta
\end{aligned}
$$


Where $u$ and $v$ are the components of the velocity along, $x$ and $y$ directions respectively, $p$ stands for the pressure, $\rho, \mu$ are density and dynamic viscosity of the air respectively, $\mathrm{g}$ is a gravitation parameter (the acceleration due to gravity), and $\theta$ is the inclination angle is shown in Figure 1 . The pressure gradient $\partial p / \partial x$ has been taken following Kongnuan and Pholuang (2012) for a human being who is given by:

$$
\frac{\partial p}{\partial x}=\frac{P}{L} \sin (\omega t), \text { for } t>0
$$

Where: $P / L$ is the constant amplitude of the pressure gradient, $\omega$ the cyclic frequency of the oscillating pressure gradient.

\subsection{Boundary and Initial Conditions}

According to Kongnuan and Pholuang (2012), the velocity components should be zero at the rigid walls (no-slip condition).

$$
u=0, v=0 \text { for } y=0, h \text { and } 0 \leq x \leq L
$$

The inlet velocity profile of the trachea the flow is assumed to be fully developed

$$
u=u(y, t), v=0, \text { for } x=0,0<y<h \text { and } t>0
$$

While the boundary conditions in the outlet section of the trachea are given by

$$
\frac{\partial u}{\partial x}=0, \frac{\partial v}{\partial x}=0, \text { for } x=L, 0<y<h \text { and } t>0
$$

The initial condition for this problem is given by

$$
u(x, \mathrm{y}, 0)=v(x, \mathrm{y}, 0)=p(x, \mathrm{y}, 0)=0, \text { at } t=0, x>0
$$

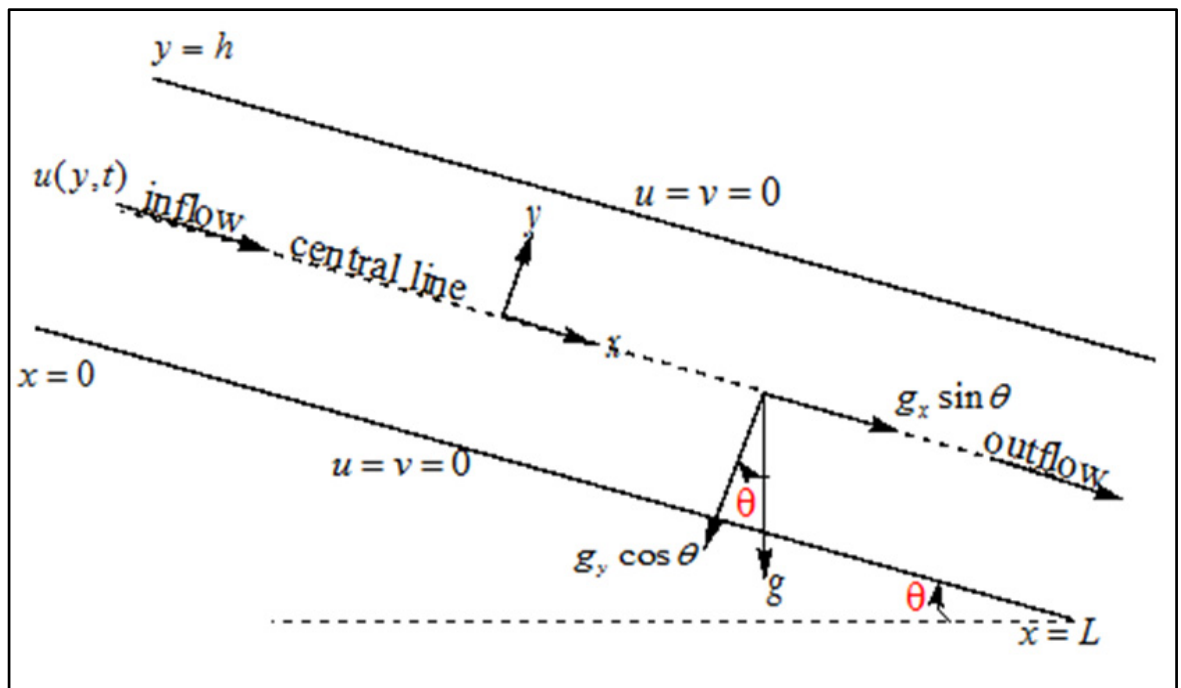

Figure 1. Sketch of the straight trachea geometry

\subsection{Method of Analytical Solution}

For equations (1-3), we see that three partial differential equations have three unknown $u, v$ and $p$ functions of three independent variables $x, y$ and $t$. Assuming fully developed airflow in these regions, $v=0$ and $u=u(y, t)$ the continuity equation (1) is satisfied and when developed flow conditions equation (3) can be omitted. Hence, we can reduce equations (1)-(3) and (4) to

$$
\frac{\partial^{2} u}{\partial y^{2}}-\frac{1}{v} \frac{\partial u}{\partial t}=\frac{p}{\mu L} \sin \omega t-\frac{\rho g}{\mu} \sin \theta, \text { where }\left(v=\frac{\mu}{\rho} \text { is kinematic viscosity }\right)
$$

Take Laplace transforms of the motion equation (9) with the boundary and initial conditions in equation (5), (8) respectively, we get 


$$
\begin{aligned}
& \frac{d^{2} u(y, s)}{d y^{2}}-\frac{1}{v}[s u(y, s)]=\frac{\omega p / \mu L}{\left(s^{2}+\omega^{2}\right)}-\frac{\rho g / \mu}{s} \sin \theta \\
& u(0, s)=0 \text { and } u(h, s)=0
\end{aligned}
$$

Where $u(y, s)$ is the Laplace Transform

$$
u(y, s)=\int_{0}^{\infty} e^{-s t} u(y, t) d t . \mathrm{s}>0
$$

The solution of equation (10) is given by

$$
\begin{gathered}
u(y, s)=A \sinh \sqrt{s / v} y+B \cosh \sqrt{s / v} y-\frac{\omega p / \rho L}{s\left(s^{2}+\omega^{2}\right)}+\frac{g \sin \theta}{s^{2}} \\
A=\frac{B(1-\cosh \sqrt{s / v} h)}{\sinh \sqrt{s / v} h}, \mathrm{~B}=\frac{\omega p / \rho L}{s\left(s^{2}+\omega^{2}\right)}-\frac{g \sin \theta}{s^{2}}
\end{gathered}
$$

Substituting equation (14) into the equation (13) becomes

$$
u(y, s)=\left(\frac{\omega p / \rho L}{s\left(s^{2}+\omega^{2}\right)}-\frac{g \sin \theta}{s^{2}}\right)\left[\frac{\sinh \sqrt{s / v} y+\sinh \sqrt{s / v}(h-y)}{\sinh \sqrt{s / v} h}\right]-\frac{\omega p / \rho L}{s\left(s^{2}+\omega^{2}\right)}+\frac{g \sin \theta}{s^{2}}
$$

The singularities in the Laplace transform are located at

$$
s=0, s= \pm i \omega, s_{n}=-\frac{n^{2} \pi^{2} v}{h^{2}} \text { and } \sqrt{\mathrm{s}_{\mathrm{n}}}=\frac{n \pi i \sqrt{v}}{h} \text {, where } n=1,2,3, \ldots . \text { and all simple poles. }
$$

By using Bromwich's integral we can find the inverse Laplace transform in equation (15), as follows:

$$
\begin{aligned}
& u(y, t)=\frac{g(h-y) \sin \theta}{2 v}-\frac{p}{2 \rho \omega}\left[e^{i \omega t}\left(\frac{\sinh (\sqrt{i \omega / v} y)+\sinh (\sqrt{i \omega / v}(h-y))}{\sinh (\sqrt{i \omega / v} h)}\right)\right. \\
& \left.+e^{-i \omega t}\left(\frac{\sinh (\sqrt{-i \omega / v} y)+\sinh (\sqrt{-i \omega / v}(h-y))}{\sinh (\sqrt{-i \omega / v} h)}\right)\right] \\
& +\sum_{n=1}^{\infty}\left(\frac{2 \mathrm{~h}^{4} p \omega / \rho \pi v}{n\left(v^{2} n^{4} \pi^{4}+\omega^{2} h^{4}\right)}+\frac{2 \mathrm{~h}^{2} \mathrm{~g} \sin \theta}{\pi^{3} v} \frac{1}{n^{3}}\right)\left(\left((-1)^{\mathrm{n}}-1\right) e^{\frac{-n^{2} \pi^{2} v t}{h^{2}}} \sin (n \pi y / h)\right)+\frac{p}{\rho \omega} \cos (\omega t)
\end{aligned}
$$

Where $\cos (\omega t)=\frac{e^{i \omega t}+e^{-i \omega t}}{2}$ and Bromwich's integral is given by

$$
u(y, t)=\frac{1}{2 \pi i} \int_{c-\infty i}^{c+\infty i} u(y, s) e^{s t} d s=\sum_{j=1}^{n} \operatorname{Res}\left(u(y, s) e^{s t}\right)
$$

The volume flow rate $(\mathrm{Q})$ through trachea is given by

$$
Q=\int_{0}^{h} u(u, t) d y
$$




\section{Results}

When the breathing period is about $1 \mathrm{Sec}$ of the breathing cycle, the cyclic frequency $\omega=\pi / 2, g=9.8 \mathrm{~m} / \mathrm{s}^{2}$ gravity acceleration, $\rho=1.148 \mathrm{~kg} / \mathrm{m}^{3}, \mu=1.82 \times 10^{-5} \mathrm{~Pa}$.Sec, $L=0.10 \mathrm{~m}$, and $h=0.02 \mathrm{~m}$ length and width of the trachea. Also, the amplitude of the oscillating pressure $\mathrm{P}=-133.32 \mathrm{~Pa}$ has been taken from the literature (Kongnuan and Pholuang, 2012), with normal body temperature $\left(37^{\circ}\right)$. From Eq. 17, Figure 2,3,4 and Figure5 has been determined after substituting the values of $t, \theta$ and $g$.

Table 1. Results of quantity of flow for different time $t$ and inclination angle

\begin{tabular}{c|ccc}
\hline$t$ & $t=1 s$ & $t=1.5 s$ & $t=2 s$ \\
\hline $0^{\circ}$ & 0.0000020907 & 1.49149 & 2.10929 \\
$15^{\circ}$ & 0.0126 & 1.50408 & 2.12188 \\
$30^{\circ}$ & 0.02435 & 1.51582 & 2.13361 \\
$45^{\circ}$ & 0.03444 & 1.52589 & 2.14369 \\
$60^{\circ}$ & 0.04218 & 1.53363 & 2.15142 \\
\hline
\end{tabular}

\section{Discussion}

Figure 2 shows the amplitude of velocity, where the higher value is in the central region, and reducing gradually to zero value close to the walls. Therefor, the behaviour of the velocity profile is in agreement with Kongnuan and Pholuang (2012) establishments of the laminar flow profile (parabola curve) According to the results in Figure 3, the maximum velocity shows around 1.44 and minimum velocity about 0.00003 at $t=2 \mathrm{~s}$ and $t=1 \mathrm{~s}$ respectively. In the other words, the velocity increases with increasing time. The effect of the inclination angle on the velocity profile is displayed in Figure 4, which shows that the increasing of $\theta\left(0^{\circ}, 15^{\circ}, 30^{\circ}, 45^{\circ}\right.$, and $\left.60^{\circ}\right)$ leads to increasing the velocity of airflow. These results close to Van Vliet et al. (2005) and Ragavan et al. (2010) when they established the inclination angle had reasonable effect.

Figure 5 illustrates that the increasing of gravity parameter $g$ leads to increasing of the airflow velocity when $\theta=30^{\circ}$. Therefore, it is supported the phenomenon that increasing of gravity $g$ may lead to reducing the flow resistance, also the velocity of air flow increases with the increase in gravity $g$. Figure 6 and Table1 shows that volumetric of the flow rate $\mathrm{Q}$ and quantity of flow increase with a higher inclination angle $\theta$ in comparison with the horizontal position $\left(\theta=0^{\circ}\right)$. Moreover, an increase of the airflow velocity leads to reducing the pressure drop in the trachea using Boyle's law gas. It can be seen that the extremely important in diving physiology of this law by increased pressure could collapse the air chambers of the diver's body, and often causes serious damage especially in the lungs (Hall, 2010). 


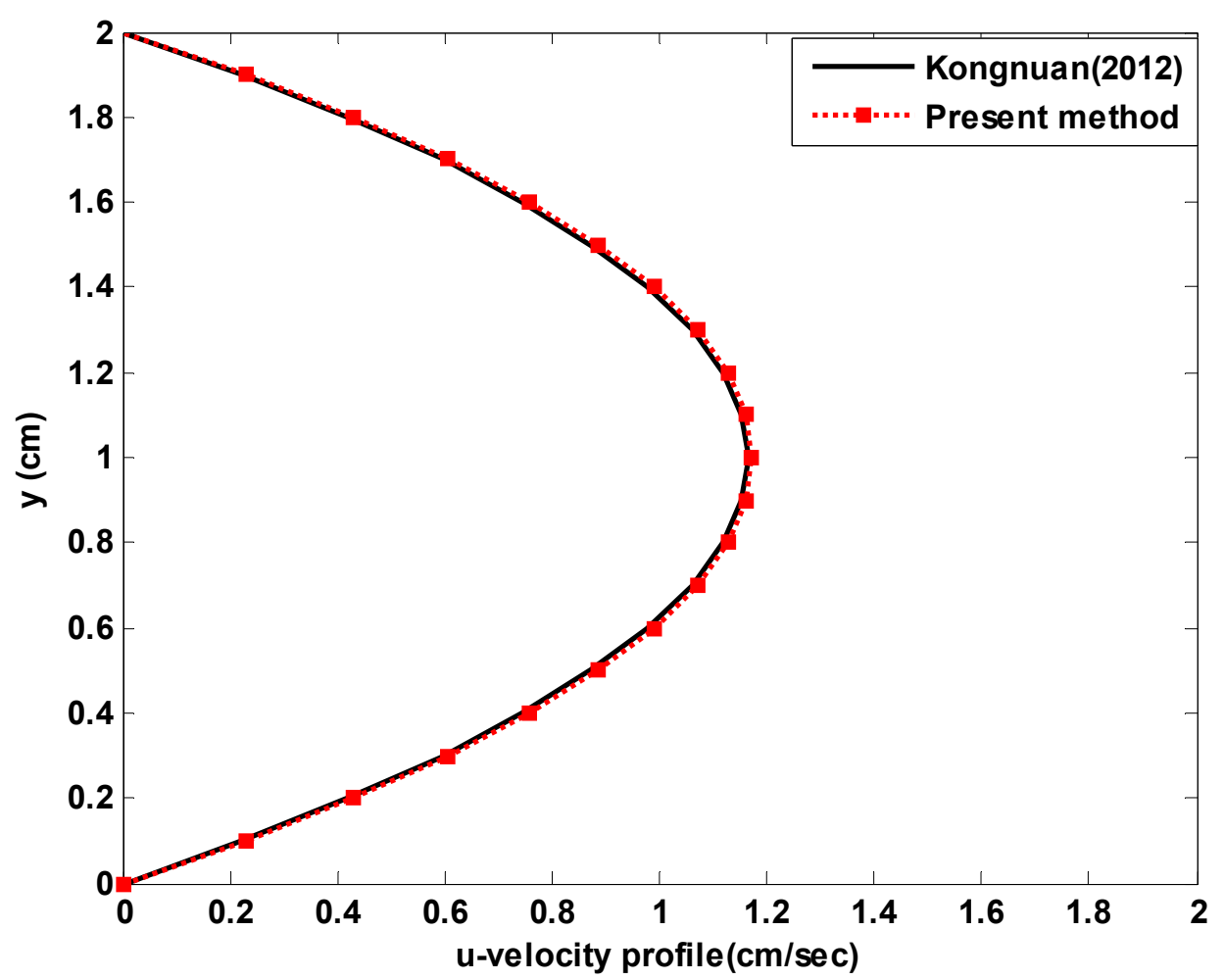

Figure 2. Velocity profile for airflow at angle $\theta=0^{\circ}$ and $\mathrm{t}=1.65$

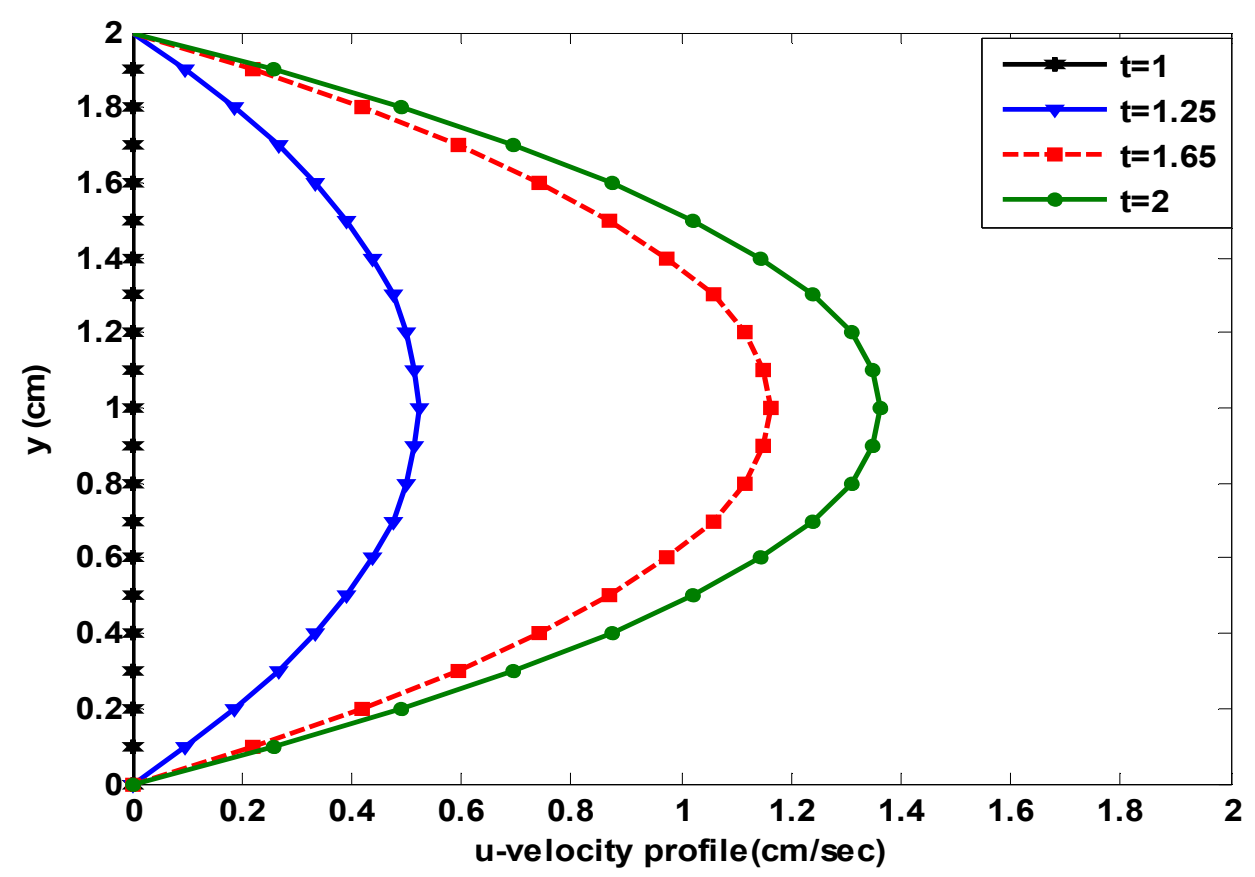

Figure 3. Velocity profile for unsteady airflow for different $\mathrm{t}$ at angle $\theta=0^{\circ}$ 


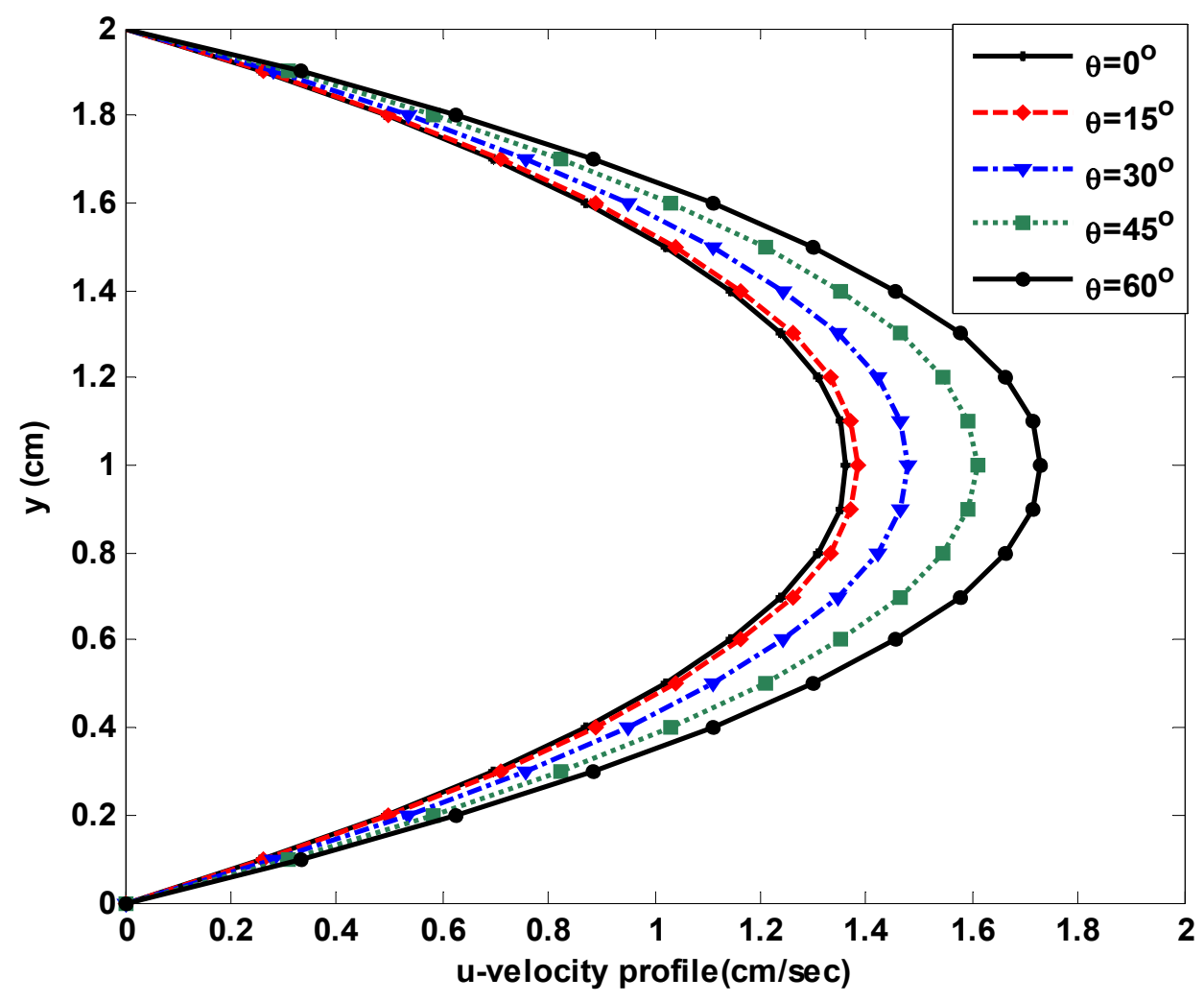

Figure 4. A variation of velocity profile for different inclination angle $\theta$ at $\mathrm{t}=2$

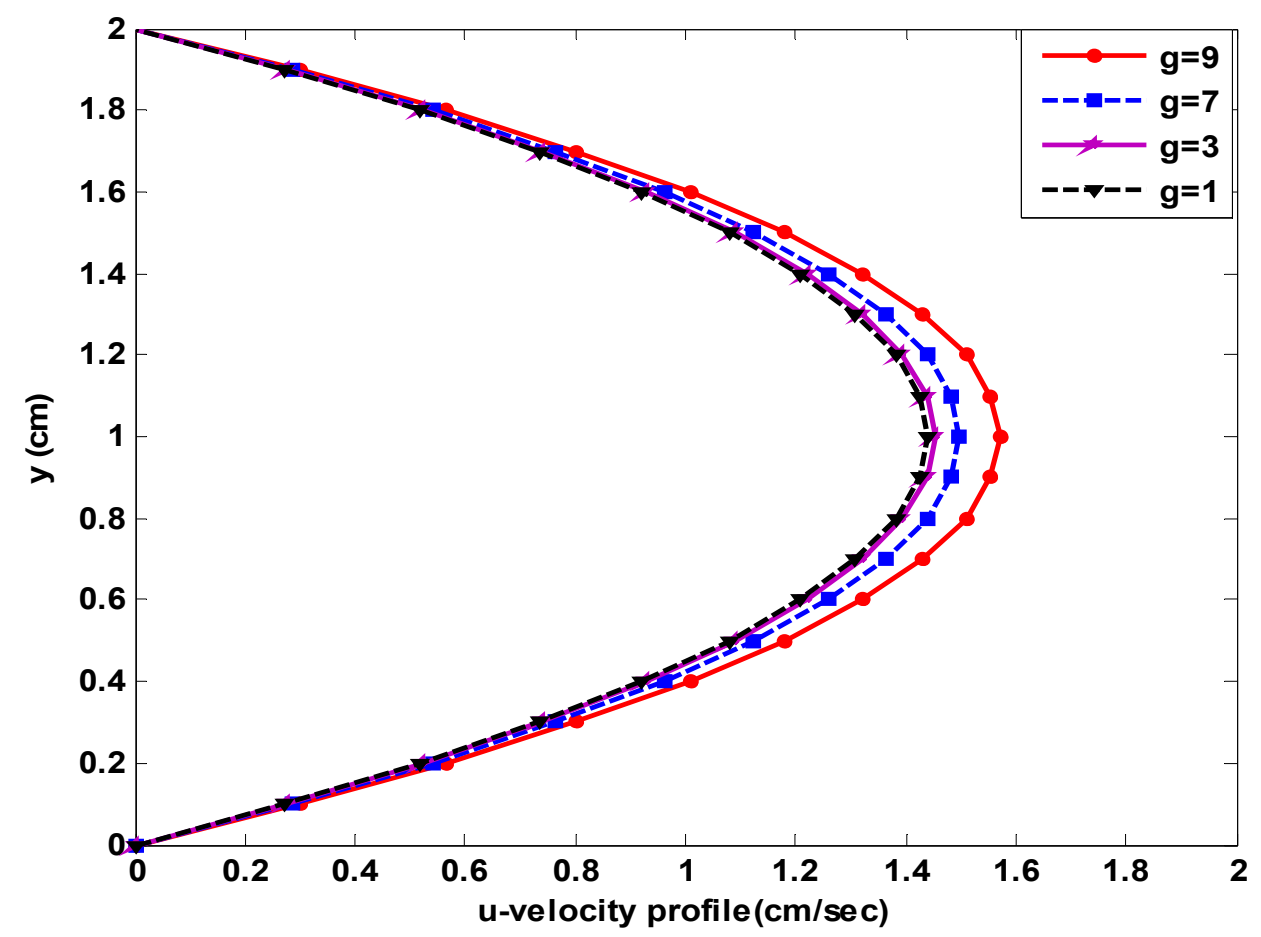

Figure 5. A variation of velocity profile for different values of $g$ at $\theta=30^{\circ}$ and $\mathrm{t}=2$ 


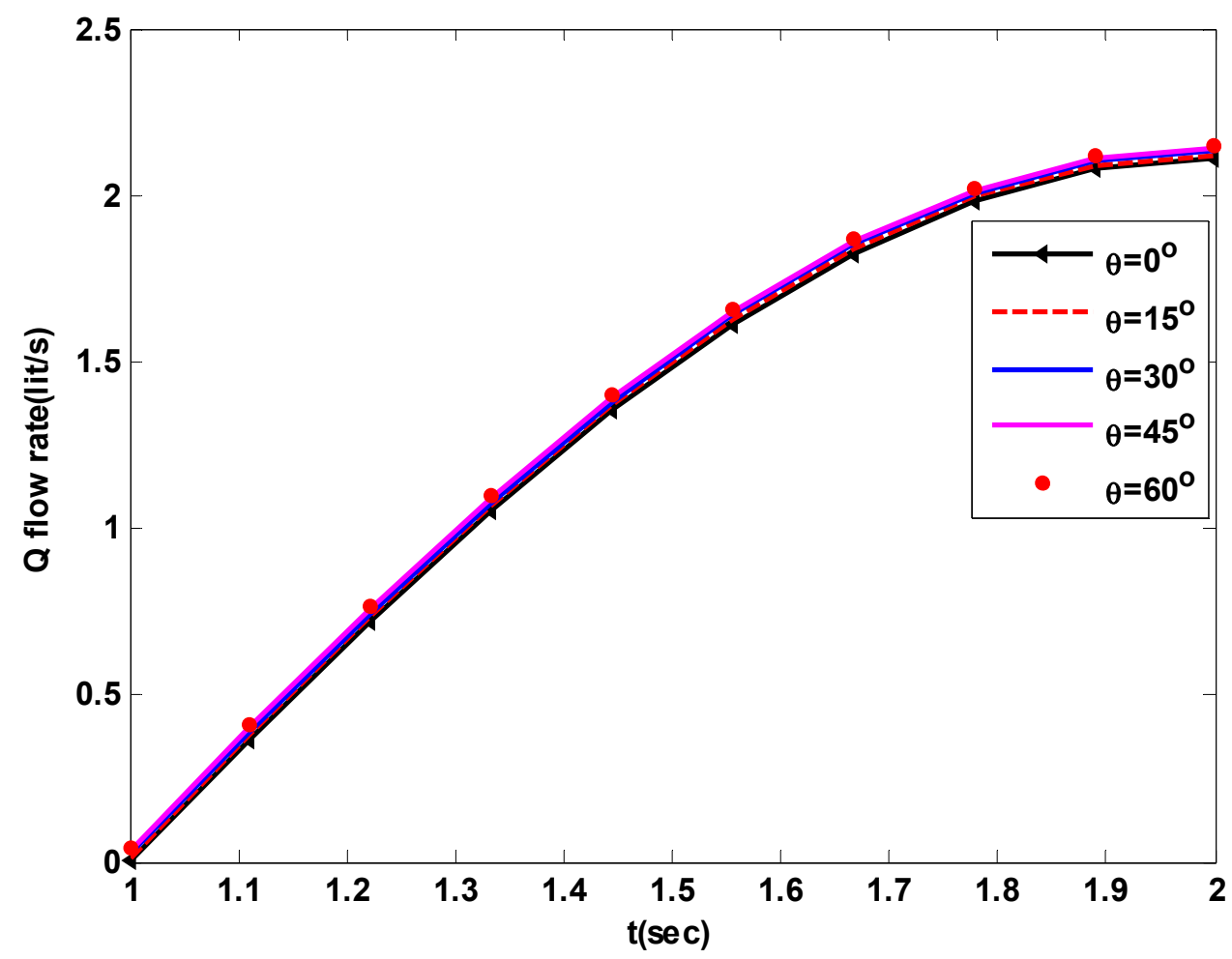

Figure 6. A variation of the volumetric flow rate for different inclination angle $\theta$

\section{Conclusion}

An analytical solution is obtained by the Bromwich integral to examine the effect of an inclination angle and the gravitational force of unsteady airflow in the trachea. The inclination angle $\theta\left(30^{\circ}, 45^{\circ}\right)$ and gravitational force $g$ reduced the pressure drop in the trachea. As a result, there is a positive effect on the increasing of airflow velocity from the trachea to the lungs. Also, the sleeping in a horizontal position leads to adverse effects for many patients, whereas the inclined position is better and depending on the slope angle, taking the benefits of gravitational force and utilizing it to improve breathing of the body.

\section{Acknowledgments}

The authors would like to thank the Ministry of Higher Education (MOHE) in Iraq for providing a research grant and Universiti Teknologi Malaysia (UTM) for supporting a research assistantship provided by Vot 00M25.

\section{References}

Baer, G. A., Terho, M., \& Tiensuu, T. (1987). Morphologic study of the adult trachea at the 7th and 12th ring. Surgical and Radiologic Anatomy, 9(2), 169-172. http://dx.doi.org/10.1007/BF02086602

Billen, E., \& Ting, T. Y. (2013). Inclined Bed Therapy and Diabetes: The Effect of Inclined Bed Therapy on Diabetes individuals. Retrieved from http://www.newmediaexplorer.org/sepp/Diabetes_IBT.pdf

Chong, M. S. F., Shahrill, M., Crossley, L., \& Madzvamuse, A. (2015). The Stability Analyses of the Mathematical Models of Hepatitis C Virus Infection. Modern Applied Science, 9(3), 250. http://dx.doi.org/10.5539/mas.v9n3p250

Efimov, N. N., Belov, A. A., Shaforost, D. A., Fedorova, N. V., \& Pryatkina, V. S. (2015). The Mathematical Model of the Coal Gasification Process in a Flow. Modern Applied Science, 9(2), 229. http://dx.doi.org/10.5539/mas.v9n2p223

Hall, J. E. (2010). Guyton and Hall Textbook of Medical Physiology. Elsevier Health Sciences, 545-546.

Inclined Bed Therapy. Retrieved June 17, 2013, from http://www.livepurehealth.net/inclined-bed-therapy/

Inclined Bed Therapy. Retrieved July 18, 2013, from http://www.electroherbalism.com/Naturopathy/Therapies/ 
MiscTherapies/Inclined_bed_therapy.html

Kongnuan, S., \& Pholuang, J. (2012). A Fourier Series-Based Analytical Solution for the Oscillating Airflow in a Human Respiratory Tract. International Journal of Pure and Applied Mathematic, 78(5), 721-733. Retrieved from http://www.ijpam.eu/contents/2012-78-5/11/11.pdf

Life And Gravity: Sleeping In A Horizontal Position May Be Bad For You. Retrieved July 17, 2013, from http://www.newmediaexplorer.org/sepp/2005/08/07/life_and_gravity_sleeping_in_a_horizontal_position_m ay_be_bad_for_you.html

Mehta, S., \& Myat, H. M. (1984). The Cross-sectional Shape and Circumference of the Human Trachea. Ann Royal College Surg England, 66, 356-8. Retrieved from http://www.ncbi.nlm.nih.gov/pmc/articles/PMC2493694/

Orakbayev, E. M., Boranbayev, S. N., Vashenko, M. P., \& Shananin, A. A. (2015). Mathematical Model of Kazakhstan Economy. Modern Applied Science, 9(8), 160. Retrieved from http://dx.doi.org/10.5539/mas.v9n3px

Ragavan, A. J., Evrensel, C. A., \& Krumpe, P. (2010). Interactions of Airflow Oscillation, Tracheal Inclination, and Mucus Elasticity Significantly Improve Simulated Cough Clearance. Chest Journal, 137(2), 355-361. http://dx.doi.org/10.1378/chest.08-2096

Roberts, C. R., Rains, J. K., Paré, P. D., Walker, D. C., Wiggs, B., \& Bert, J. L. (1998). Ultrastructure and Tensile Properties of Human Tracheal Cartilage. Journal of biomechanics, 31(1), 81-86. http://dx.doi.org/10.1016/S0021-9290(97)00112-7

Rowley, J. A., Mc Gowen, C., Lareau, S., Fahy, B., Garvey, C., \& Sockrider, M. (2009). What Is Obstructive Sleep Apnea In Adults? American Journal of Respiratory and Critical care Medicine, 179(12).

Satpahi, D. K., Kumar, R., \& Chandra, P. (2003). Unsteady-State Laminar Flow of Viscoelastic Geal and Air in a Channel: Application to Mucus Transport in cough Machine Simulating Trachea. Mathematical and Computer Modelling, 38,63-75. http://dx.doi.org/10.1016/S0895-7177(03)90006-9

Shangytbayeva, G. A., Karpinski, M. P., Akhmetov, B. S., Yerekesheva, M. M., \& Zhekambayeva, M. N. (2015). Mathematical Model of System of Protection of Computer Networks against Attacks DOS/DDOS. Modern Applied Science, 9(8), 106. http://dx.doi.org/10.5539/mas.v9n8p106

Stroiteleva, T. G., \& Vukovich, G. G. (2015). Mathematical Modeling of Workflows in Production Systems. Modern Applied Science, 9(3), 173. http://dx.doi.org/10.5539/mas.v9n3p173.

Tsangaris, S., \& Vlachakis, N. W.(2003). Exact solution of the Navier-Stokes equations for the oscillating flow in aduct of a cross-section of theright-angled isosceles triangle, Z. Angew. Math. Phys, 54, 1094-1100. http://dx.doi.org/10.1007/s00033-003-2013-z

Tu, J., Inthavong, K., \& Ahmed, G. (2013). Computational Fluid and Particle Dynamics in the Human Respiratory System. New York, Springer, 32-35. http://dx.doi.org/10.1007/978-94-007-4488-2

Van Vliet, P. W., Ellis, E. R., \& Hila, J. (2005). The Effect of Angle and Oscillation on Mucous Simulant Speed in Flexible Tubes. Physiotherapy Research International, 10(3), 125-133. http://dx.doi.org/10.1002/Praia. 2

\section{Copyrights}

Copyright for this article is retained by the author(s), with first publication rights granted to the journal.

This is an open-access article distributed under the terms and conditions of the Creative Commons Attribution license (http://creativecommons.org/licenses/by/3.0/). 